\title{
Effects of Incentives and Genetics on Food Choices and Weight Phenotypes in the Neuroendocrine Gene Tubby Mutant Mice
}

\author{
George C. Davis ${ }^{1,2}$, Johanna Jacob ${ }^{2}$ and Deborah J. Good ${ }^{* 2}$ \\ ${ }^{I}$ Department of Agricultural and Applied Economics and ${ }^{2}$ Department of Human Nutrition, Foods and Exercise, \\ Virginia Tech, Blacksburg, VA 24061, USA
}

\begin{abstract}
Food intake and obesity related phenotypes are greatly affected by economic factors and yet very little is known about the interaction of economic factors, genetics, behavior, and obesity phenotypes. Recent human population research suggests that a decreasing price of high fat food relative to low fat food has contributed to the current obesity epidemic in humans. The two key elements in this argument are choice and costs. We incorporate these key elements in a closed economy mouse model to study the interactions of economics, genetics, and obesity related phenotypes, using normal mice, and mice with a mutation in the hypothalamus-expressed Tub gene, which has a phenotype of adult onset obesity. Results for both genotypes indicate that as the price of the high fat food falls, consumption of that food increases and consumption of the low fat food declines, but not enough to offset the increase in high fat food so total intake and weight increases, with no statistically-significant differences between genotypes. These results are in contrast to previous literature based on an ad lib, no choice food setting. In addition, in our closed economy model, the Tub mutant showed a numerical and statistically significant increase in body fat percentage and glucose intolerance, whereas these increases were only numerical for the normal mice. Both genotypes showed numerical but statistically insignificant increases in leptin and ghrelin levels. These results show that accounting for choice in neuroeconomic studies is important to understanding the complex regulation of intake, body weight and other related phenotypes.
\end{abstract}

Keywords: Body fat, body weight, closed economy, food choice, food intake, food price, glucose tolerance test, operant chambers, tub/tubby.

\section{INTRODUCTION}

A suspected major contributor to the obesity epidemic is the increased consumption of high energy-dense food relative to low energy-dense food [1-3]. Although there are numerous environmental factors affecting this food consumption pattern, economic factors appear especially important [2, 4-7]. An important economic factor contributing to this consumption pattern and hence the obesity epidemic has been the decreasing price of high fat food relative to low fat food [4-6, 8-10]. Very little is known about the interaction of food prices, genetics, behavior, and biological, or specifically obesity related phenotypes, such as weight gain, body fat percentage, or glucose intolerance, to name a few. More generally, "[t]here is a pressing need to understand at a fundamental level the interactions between genes and economic change in the environment" [11]. This research utilizes a mouse model experimental design that mimics this human economic environmental change in order to begin to gain insights on the interactions of food prices, genetics, behaviors, and phenotypes.

The research design is influenced by research streams in three feeding environment paradigms [12]: (i) ad lib feeding with no food choice and no cost, (ii) closed economy with no food choices but a food cost and (iii) closed economy with

*Address correspondence to this author at the Department of Human Nutrition, Foods, and Exercise, 1981 Kraft Drive (0913), ILSB Room 1020, Blacksburg, VA 24061, USA; Tel: (540) 231-0430; Fax: (540) 231-5522;

E-mail: goodd@vt.edu food choices and costs. In the ad lib paradigm animals have unlimited access to a food at no cost. This is perhaps the most common paradigm used to study differences across genotypes and/or diets focusing on obesity related phenotypes as found in the diet induced obesity literature (e.g., [13-16]). In a closed economy paradigm the animal must obtain its entire food intake during the experimental conditions due to its own actions in response to some activation device, such as a lever press, and there is no supplemental food available during non-experimental time $[17,18]$. In the closed economy with no food choices but a food cost, the main focus has been on how intake attributes, such as feeding bout frequency, length, and intake are related to cost, and more recently exploring differences in genotypes in these dimensions [11, 19]. Finally, there is a wellestablished closed economy literature with choice and costs. In this literature the focus has been on the behavioral implications of choice and costs of reinforcers, not just food, with the main outcomes again being intake attributes, but including substitutability relationships between reinforcers (e.g., [20-22]. We are unaware of any closed economy studies with food costs and choice looking at genotype differences, or more importantly the obesity related phenotypes linked to diet, as considered in the ad lib studies.

The two key elements of the argument that the falling price of high fat food relative to low fat food contributes to obesity [4-6, 8-10] are price and choice. There is no reason to believe that outcomes in an environment without these elements will generalize to environments with these elements. This is especially true with respect to intake 
related biological phenotypes. The logic chain is straightforward. The nutritional composition ('good' and 'bad') of total food intake is the major determinant of dietary quality and hence obesity related phenotypes. In a choice setting, the diet composition by definition will depend on the choices made, which in turn will depend on prices.

Economics provides some useful unifying concepts for discussing these issues [23, 24]. The key concepts needed here are the law of demand and substitutability. As depicted graphically in introductory textbooks, the law of demand is an intuitive two dimensional negative relationship: as the price of the good increases the quantity consumed of the good decreases, ceteris paribus, meaning all other determinants held constant (e.g. other prices held constant). Through novel experiments, several authors have demonstrated that mice and other species follow this 'simple' law of demand and that food intake will decrease as price increases [11, 19, 25-27]. However, in the context of food related behavior and biological outcomes it is extremely important to recognize the theory of demand that generates this simple law of demand is based on an environment consisting of multiple goods, each with their own price [28]. Consequently, the demand functions generated from the theory of demand are multidimensional constructs and the quantity demanded of one good depends not only on its own price but also on the price of other goods (cross prices) as well. For example, the quantity of gasoline consumed at one service station is certainly affected by its price there (own price), but is also affected by the price of gasoline across the street (cross price). Goods are classified as substitutes or complements based on their cross price effects. Goods are considered substitutes if the cross price effect is positive: as the price of one increases, consumption of that good will decrease via the 'simple' law of demand, but consumption of the other good will increase in a compensatory or substitution fashion via the cross price effects. Alternatively, two goods are considered complements if, as the price of one good increases, the consumption of both goods decreases. Finally, if two foods are considered independent, then the consumption of one good is not affected by the price of the other.

The argument that declining high fat food prices have contributed to obesity related phenotypes is therefore based on choice and substitutability. Accounting for choice and consequently cross price effects (substitutability) is especially important for phenotypes related to food intake and obesity because different foods have different nutritional characteristics, which in turn can affect obesity related phenotypes in different ways. For example, the weight of an animal could decrease or increase depending on the relative consumption of the two foods and their nutritional characteristics. Note then this does not imply weight will necessarily decrease if the price of a food is increased. If the two foods are substitutes, consumption of the other food would increase and the nutritional characteristics of this other food may contribute more to weight or other obesity related phenotypes than the food whose price increased. The 'general' law of demand accounts not only for changes in consumption of the good whose price changed, but also how that change in price may have cross-over effects on the consumption of other goods via choice (the cross-price effect). Of course, similar to a single food case, in a two- food setting there also may be differences between genotypes in behavioral responses that may lead to differences in obesity related phenotypes.

The purpose of this research is to extend the current literature regarding mouse neuroeconomic genotypes and food intake to ask if food choice and genotype affect obesity related phenotypes in a closed economy food costs choice setting. In addition to reporting on food intake (low fat, high fat, total) and body weight, we also consider several phenotypes that have not been examined in previous food cost studies: percentage of body fat, serum ghrelin levels, serum leptin levels, and glucose tolerance. We chose to investigate differences between mice with a mutation in the Tub gene (MUT) and normal mice, both of which are genotypes that have not been compared in the literature of operant behavior and food intake. The Tub gene is expressed in the hypothalamus $[29,30]$, a major central nervous system site for central control of body weight. The mutant mouse model for the Tub gene displays adult-onset obesity with a phenotype of slight hypophagia and reduced overall physical activity levels in an ad lib, no choice food setting, [31]. In addition, both anorexigenic and orexigenic proteins/peptides are downregulated in the arcuate hypothalamus of $t u b / t u b$ mice, suggesting that food intake behaviors in these mice may be very complex $[32,33]$. We conjecture that studies measuring total food intake which use ad libitum food intake with no choice of food will be misleading in a closed economy environment with food choices and costs, especially when the price of high fat food is decreasing relative to a low fat food. We hypothesize that as the price of high fat food decreases relative to low fat food, we will observe increases in obesity related phenotypes for both genotypes, with an exacerbation of the trends for the obesityprone mutant animal.

\section{MATERIALS AND METHODS}

\section{Animals and Environment}

The experimental design, protocol, and sample size is very similar to that of previous closed economy feeding studies $[21,34]$. Six Tub Mutant (MUT) $\left.\left(\mathrm{B} 6(\mathrm{Cg})-\mathrm{Tub}^{\text {tub }} / \mathrm{J}\right)\right)$ and four Wildtype (WT) (C57BL/6) female mice were obtained from colonies maintained at Virginia Tech University, from breeding pairs originally obtained through The Jackson Labs (Bar Harbor, ME). Each WT mouse was a sibling to at least one MUT animal. All animal experiments were approved by and followed animal welfare standards set forth by the Institutional Animal Care and Use Committee at Virginia Tech. The Virginia Tech animal facility room where all experiments were conducted maintained temperatures averaging $20.1 \mathrm{C}$, humidity averaging $36.1 \%$ and a light cycle of 9 AM-5 PM daily. The breeding room had similar temperature and humidity levels, but maintained a light cycle of 7 AM-7 PM daily. Mice were genotyped using published procedures [35]. At 6-8 weeks of age all mice were moved to individual shoebox cages with access to water and two jars of $20 \mathrm{mg}$ pellets ad lib. One jar contained a low-fat (LF) diet based on the AIN-93g formulation with $16.7 \%$ fat, $19.1 \%$ protein, and $64.2 \%$ carbohydrates [36]. The other jar contained a modified high-fat (HF) diet $(35.2 \%$ fat, $19 \%$ protein, and $45.8 \%$ carbohydrates). The diets were formulated to be isocaloric to control for the potential 
confounding effects of different calorie levels and were supplied by Bio-Serv. (Frenchtown, NJ). Table 1 provides the specific nutrient contents for both diets. Mice remained in the shoebox cages until they had adapted to the new food, which usually took $2-5$ days. After a $12 \mathrm{hr}$ fast, mice were then moved to individual operant chambers measuring $18 \mathrm{x}$ $20 \times 14 \mathrm{~cm}$ with a steel rod floor. Two levers protruded on one wall of the operant chamber and, internal to the levers, two recessed food troughs. Small cue lights above each lever and each trough indicated operational status (Fig. 1A). Ad lib water was available from a spout centrally located on the wall opposite the levers. Each operant chamber was housed within a sound attenuated cubicle $(77 \times 50 \times 49$ cm) containing a ventilation fan and house light. Operant chambers and housing cubicles, along with computer software, were made by LaFayette Instrument Company (Lafayette, IN). The animals were supplied with a Shepherd Shack (Shepherd Specialty Papers, Milford, NJ) and a neslet (Ancare, Bellmore, NY). Mice remained in the operant chamber through the entirety of the experiments, with the exception of 30 minutes at the end of each day when they were removed for cage cleaning and phenotypic measurements.

Table 1. Macronutrient Contents of the High Fat (35\% Fat) and Low Fat (16.7\% Fat) Pellets

\begin{tabular}{|l|l|l|l|}
\hline Macronutrient & Gram \% & Kcal/Gram & \%Kcal \\
\hline \hline 16.7\% Fat Diet & & & \\
\hline Carbohydrate & 60.4 & 2.42 & 64.2 \\
\hline Protein & 18.1 & 0.72 & 19.1 \\
\hline Fat & 7.0 & 0.63 & 16.7 \\
\hline Fiber & 4.8 & & \\
\hline Total & & $\mathbf{3 . 7 7}$ & $\mathbf{1 0 0}$ \\
\hline$\underline{\mathbf{3 5 \%} \text { Fat Diet }}$ & & & \\
\hline Carbohydrate & 43.2 & 1.73 & 45.8 \\
\hline Protein & 18.1 & 0.72 & 19.0 \\
\hline Fat & 14.8 & 1.33 & 35.2 \\
\hline Fiber & 15.2 & & \\
\hline Total & & $\mathbf{3 . 7 8}$ & $\mathbf{1 0 0}$ \\
\hline
\end{tabular}

\section{Shaping and Food Procurement Schedule}

As indicated, the goal of this experiment was to mimic the observed decrease in the price of high fat food relative to low fat food observed in the human environment, and determine how the mice would respond behaviorally and biologically. Consequently, mice first had to be acclimated to a high price level, which for this study is 40 lever presses per pellet, also known as a consumatory fixed ratio (CFR). Food levers and dispensers were operational from 5:00 PM until 9:00 AM everyday for a 16:8 hr feeding/non-feeding cycle. During the feeding cycle, a purchase transaction proceeded as follows. To begin, a cue light above each lever was on. Once the mouse engaged the lever for the chosen food, the cue light of the other food turned off and the lever for that food became inactive. Once the mouse completed all the lever presses required to dispense a pellet for the chosen food, the cue light over the lever would turn off, the cue light over the associated trough would turn on for two seconds, and the pellet would be delivered. This would complete the transaction and the system would reset with both lever cue lights turned back on, and the trough lights turned off.

A.

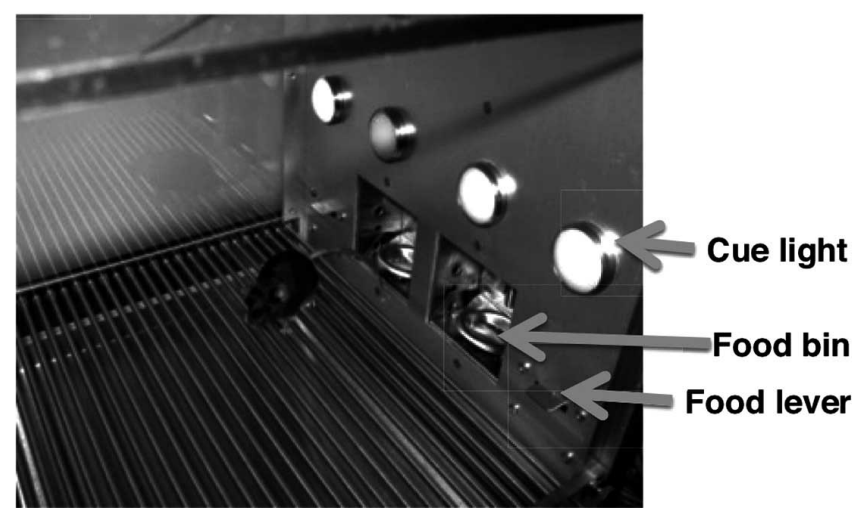

B.

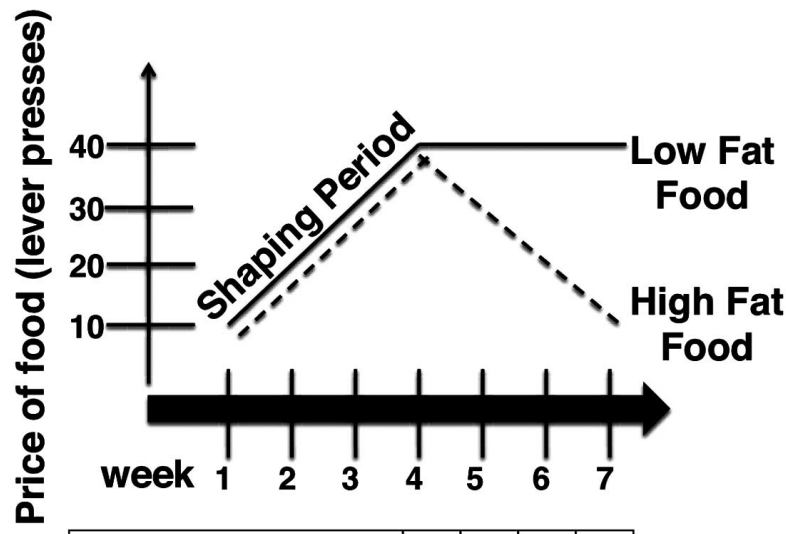

\begin{tabular}{|l|l|l|l|l|}
\hline Food Intake & X & X & X & X \\
\hline Body Weight & X & X & X & X \\
\hline Body Fat & X & X & X & X \\
\hline Ghrelin & X & & & X \\
\hline Leptin & X & & & X \\
\hline Glucose Tolerance & X & & & X \\
\hline
\end{tabular}

Fig. (1). The operant chamber set up and experimental design. (A) A picture of the operant chamber design from LaFayette Instruments. The arrows point to food levers, which are used for pressing (price), food bins, where the food is delivered, and operant cue lights which indicate to the mouse which lever is active. (B) Experimental design and measures. Both WT and MUT animals were shaped with food price for both low fat and high fat going up by 10 presses each $\sim 7-10$ days. When the mice reached prices of 40 presses for both low fat and high fat, the experimental schedule was followed. At week one (price 40 for both foods), all measures were conducted (GTT, blood draws, food intake, body weight, body fat. Each week thereafter, the price of the high fat diet was reduced, and parameters indicated were measured. 
During the four week shaping period, the mice progressed through the following equal CFR schedules for the low fat and high fat foods with equal light intensity:1010, 20-20, 30-30, and 40-40 presses per pellet (Fig. 1B). Each schedule was in place for 7-10 days and foods were rotated weekly to discourage lever bias. The weight and consumption of each mouse was monitored daily to ensure they were eating and maintaining weight.

Once the mice reached the starting prices of 40-40, they were then progressed through the following CFR schedules for the low fat and high fat foods, respectively: 40-40, 40-30, 40-20, and 40-10 presses per pellet (Fig. 1B). Schedules were in place for 7-10 days and foods were rotated weekly when prices changed. In an attempt to help reduce learning time, conditioned stimulus response paradigms [37] using a light cue to signal food delivery were utlized. In this study, the cue light for low fat high-priced food was set at a slightly lower illumination intensity than the high fat low-priced food. The Animal Behavior Environement Test (ABET) II software from Lafayette Instruments controlled the operant chambers and recorded the number of presses and pellets released. Use of cue lights in operant chambers is described in previous reports on food seeking behavior (e.g., [38]).

\section{Outcome Procedures and Measures}

A schematic of the outcomes can be found in Fig. (1B). In addition to daily intake and weight measures, body fat percentage was measured weekly with a whole body magnetic resonant imaging (MRI) using a Bruker LF90 NMR analyzer (Bruker Corporation, Billrica, MA). The MRI was conducted on the last day of each schedule (for the starting schedule it was conducted the day before the starting schedule began). A glucose tolerance test (GTT) was conducted on each mouse at the beginning of the 40-40 CFR schedule and again at the end of the final 40-10 CFR schedule. Prior to the test, mice were food deprived for 12 hours. Tail blood was taken for the fasted measurement and glucose $(2 \mathrm{~g} / \mathrm{kg}$ in sterile PBS) was injected intraperitoneally (IP). Tail blood was obtained at 15, 30, 60, 90 and 120 minutes following the injection. Glucose in tail blood was measured using a glucometer (One-Touch Basic, Lifescan, Milpitas CA). At the beginning of the 40-40 CFR schedule, at the end of the final 40-10 CFR schedule, and one day prior to the day of the GTT, blood samples were collected via the cheek pouch bleeding procedure [39]. Blood samples were processed to obtain leptin and ghrelin levels using commercially available kits (Alpha Diagnostics Mouse Leptin Elisa, San Antonio, TX; Millipore Mouse Total Ghrelin Elisa Kit, Billerica, MA). Vaginal smears were taken daily for estrous cycle determination with no significant differences with respect to stage of cycle and other measures noted (data not shown).

\section{Data Analysis}

For data analysis, measures were either daily (food intake and body weight), weekly (body fat percentage), or beginning and ending (ghrelin, leptin, and GTT) for each mouse. Because intake and weight were measured daily, we used the mean values over the last four days of each schedule. Body fat percentage, ghrelin and leptin levels, and GTT were used as measured. Parameters are estimated using repeated measurement two-way and one-way ANOVAs and post hoc Tukey honestly significant difference (HSD) tests. In presenting and discussing the results we take care to distinguish between numerical significance (or trends) versus statistical significance as admonished in several places (e.g. [40]). In addition, for reasons discussed several places as well (e.g. [41]), we present $P$-values as evidence of strength of significance. However, for conciseness and following convention, we use a 0.05 cutoff rule for indicating significance, while recognizing this common value is subjective and somewhat arbitrary.

\section{RESULTS}

\section{Effect on Food Intake}

Prior to discussing the differential price effects, it should be noted that because the prices are equal during the shaping period, the consumption distribution between the low fat and high fat (isocaloric) foods will give an indication of food preference. Over the shaping period average consumption for the MUT of low fat and high fat was 53.85 and 47.47 pellets per day, respectively. Though there was a slight numerical preference for the low fat food, the difference was not statistically significant $(\mathrm{t}=1.16, P=0.25)$. For the WT, average consumption of low fat and high fat was basically identical at 49.35 and 49.02 pellets per day, respectively $(\mathrm{t}=$ $0.04, P=0.96)$. These differences across genotypes are not significant: low fat food $(\mathrm{t}=0.74, P=0.46)$ and high fat $(\mathrm{t}=$ $-0.23, P=0.82)$. So when procurement costs were the same the two food types were thus equally and similarly acceptable and palatable to both genotypes.

The effects of lowering the price of the high fat food on the quantity of high fat, low fat, and total pellets consumed are shown in Fig. (2). The lowering of the price of high fat food increased high fat food consumption (the simple law of demand or own price effect) and this effect was statistically significant $(F(3,24)=5.86, P<0.01)$. With the exception of consumption at the high fat price of 30 , MUT consumption was numerically higher but there was no statistically significant main genotype effect $(F(1,24)=0.34, P=0.57)$ or price-genotype interaction effect $(F(1,24)=1.68, P=$ $0.19)$ (Fig. 2A). From the initial price of 40 to the final price of 10 , mean consumption of the high fat diet across genotypes more than doubled from 46 pellets per day to 110 as predicted by the 'simple' law of demand. The complete post hoc Tukey HSD tests for differences between points of consumption indicated the following were statistically different: $10>30$ (HSD-test $=4.36, P=.03$ ), $10>40$ (HSDtest $=5.34, P<.01)$, and $20>40($ HSD-test $=4.22, P=.03)$. Adjacent pairs were not statistically different, indicating that the change in food intake was gradual.

The effect of lowering the price of the high fat food on the quantity of low fat food consumption (the cross price effect) showed numerically a substitution or compensation effect as the intake of low fat food decreased as the price of high fat food decreased (Fig. 2B) but this effect was not statistically significant $(F(3,24)=2.34, P=0.09)$. As the figure shows the overall pattern of low fat food consumption decline was very similar for the MUT and WT and this is confirmed statistically as there was no statistically significant main genotype effect $(F(1,24)=0.13, P=0.73)$ or genotype-price interaction effect $(F(3,24)=1.77, P=$ 0.18 ). 

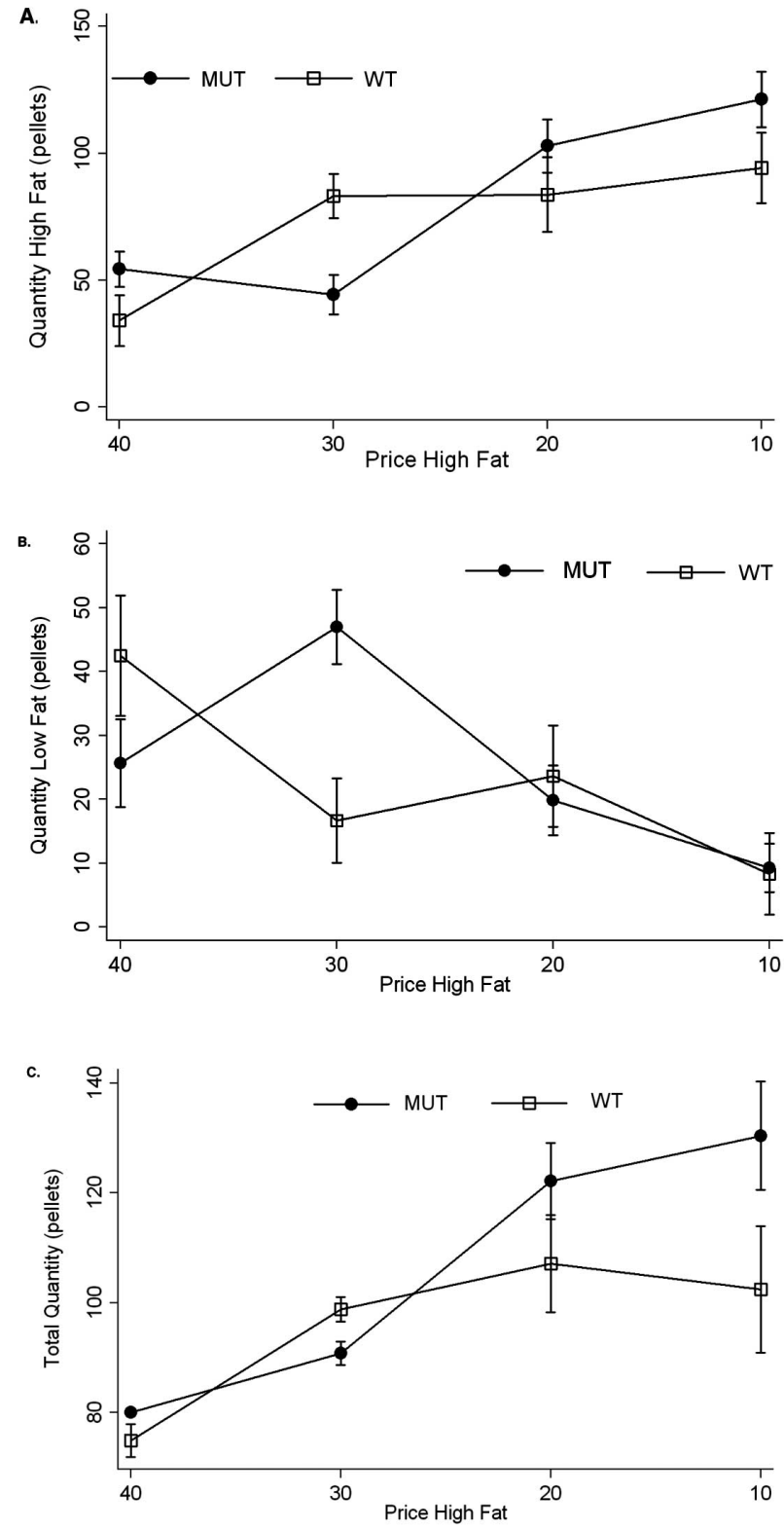

Fig. (2). Food consumption group means \pm S.E. (A) high fat consumption, (B) low fat consumption, and (C) total consumption versus price change by genotype.

Because weight is affected by total caloric intake (not just high fat or low fat), Fig. (2C) shows the effects of the changing price on the quantity of total pellets consumed. The figure shows an obvious increase in total food intake as the price of high fat food decreases and this numerical result was statistically significant as well $(F(3,24)=7.64, P<0.01)$. The statistically significant differences in consumption points from the HSD tests were: $10>30$ (HSD-test $=3.87, P$ $=.05), 10>40($ HSD-test $=6.32, P<.01)$ and $20>40$ (HSD-test $=5.85, P<.01$ ). Fig. (2C) also indicates the MUT and WT consumption patterns were overall quite similar and this was confirmed as there was no significant main genotype effect $(F(1,24)=2.27, P=0.15)$ or genotype-price interaction effect $(F(3,24)=1.32, P=0.29)$.

\section{Effects on Body Weight and Body Fat Percentages}

The effect of the changing price on weight is shown in Fig. (3A). As the price of the high fat food decreased, weight increased and this increase was statistically significant $(F(3,24)=12.45, P<0.01)$. The statistically significant differences in weight points from the HSD tests were: $10>$ 20 (HSD-test $=4.57, P=.02), 10>30($ HSD-test $=8.52, P<$ $.01), 10>40$ (HSD-test $=7.41, P<.01), 20>30$ (HSD-test $=3.95, P=.03)$. The figure shows that the relationship between weight and the price was numerically very similar for the MUT and WT and there was no significant main genotype effect $(F(1,24)=0.18, P=0.68)$ or genotype-price interaction effect $(F(3,24)=1.05, P=0.39)$. Thus, regardless of genotype, these data suggest an overall weight gain as the price of high fat food is decreased, which is consistent with the human economic environment argument.

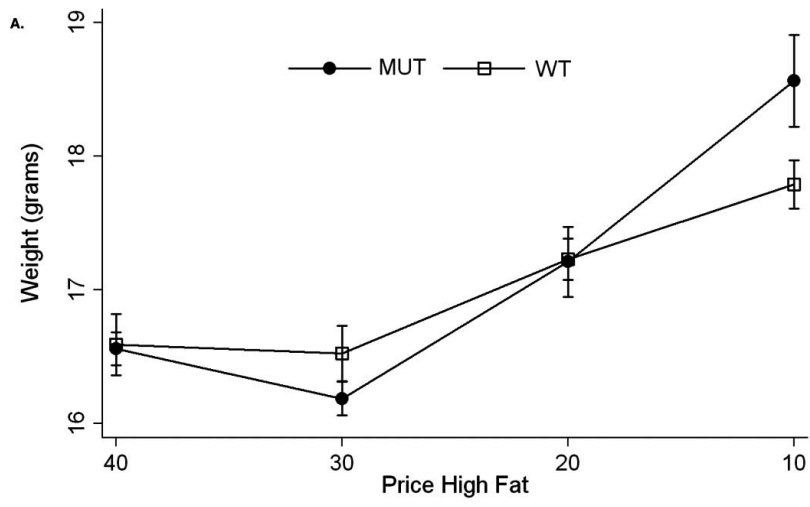

B.

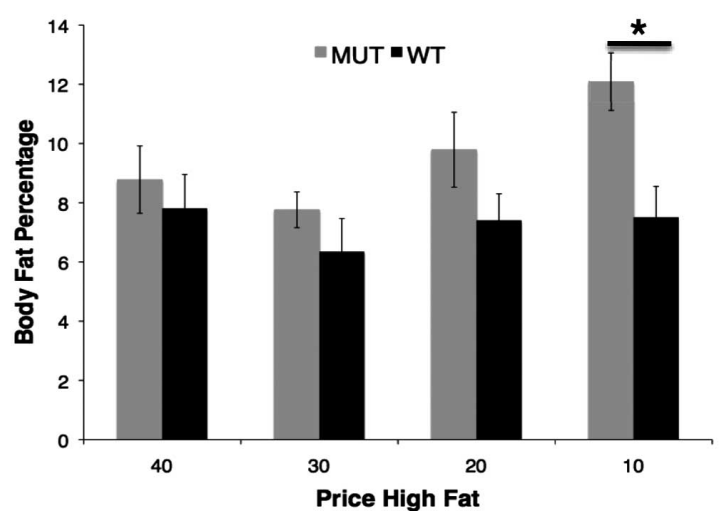

Fig. (3). Body weight (A) and body fat (B) group means \pm S.E. versus price change by genotype. ${ }^{*} P<0.05$ MUT $v$ WT for the entire body fat price relationship schedule.

There are more differences across genotype in terms of the change in body fat percentage (Fig. 3B). As the price of high fat food decreased body fat percentage increased numerically and this was statistically significant $(F(3,24)=$ 4.78, $P<0.01$ ). In addition, as is visually evident from Fig. (2B), the MUT tended to increase body fat percentage numerically more than the WT and this difference was statistically significant as well, as there was a significant genotype effect $(F(3,24)=20.50, P<0.01)$ but the interaction effect is not significant $(F(3,24)=2.42$, 
$P=0.09$ ). One way ANOVA analysis by genotype showed that the positive price effects were significant for the MUT $(F(3,15)=9.32, P<0.01)$. The statistically significant differences in body fat percentages for the MUT from the HSD tests were: $10>30$ (HSD-test $=7.13, P<.01)$ and $10>$ 40 (HSD-test $=5.45, P<.01)$. Alternatively, for the WT mice though there is a similar numerical pattern to increasing body fat with the MUT, the change is not as dramatic and there were no statistically significant differences in body fat percentage related to price $(F(3,9)=0.52, P=0.68)$. Results therefore indicate that body fat levels in MUT animals increased as the price of the high fat food decreased.

\section{Effects on Ghrelin and Leptin Levels}

Fig. (4) shows the relationship between price and the ghrelin levels (Fig. 3A) and leptin levels (Fig. 4B), which were only measured at the beginning and end of the experiment. Together the results clearly show that mean ghrelin and leptin levels numerically increased between the high price level of 40 and the low price of 10 . However, for ghrelin there were no statistically significant price effects $(F(1,7)=0.15, P=0.71)$, genotype effects $(F(1,7)=0.35, P$ $=0.57)$, or price-genotype interaction $\operatorname{effects}(F(1,7)=0.06$, $P=0.80)$. Similarly for leptin there were no statistically significant price effects $(F(1,7)=1.84, P=0.22)$, genotype effects $(F(1,7)=0.16, P=0.70)$, or price-genotype interaction effects $(F(1,7)=0.80, P=0.40)$.
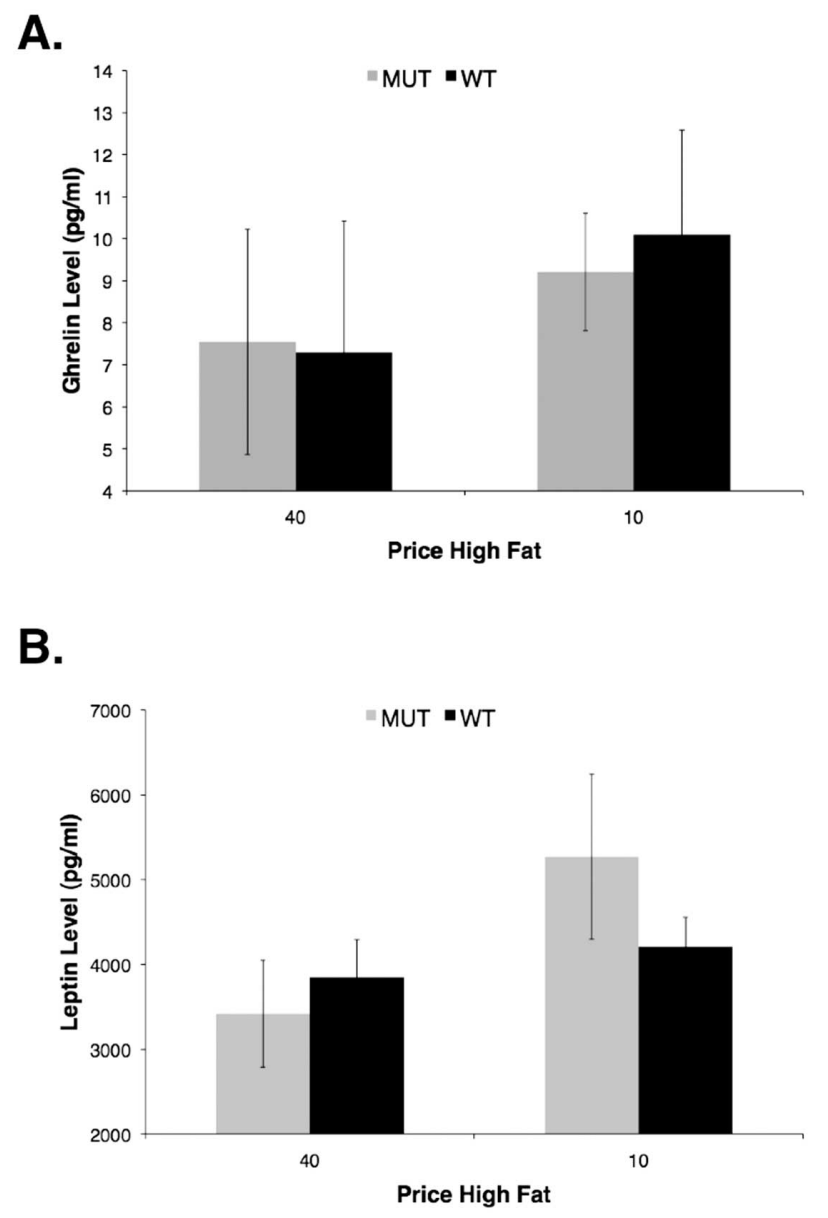

Fig. (4). Changes in ghrelin (A) and leptin (B) group mean \pm S.E. versus price change by genotype.

\section{Effects on Glucose Tolerance Test}

Fig. (5) shows the relationship between price and glucose tolerance test results for both genotypes. The average blood glucose curves for each genotype given a glucose tolerance test after the high and low price schedules are shown in Fig. (5A) (WT) and Fig. (5B) (MUT). In MUT animals, blood glucose levels declined numerically more slowly following low priced high fat food price schedule than for WT. This is shown more clearly in Fig. (5C), which displays the area under the curve (AUC) for both genotypes at each price schedule. The AUC under the curve numerically increased for both MUT and WT when going from the high price to the low price, with the effect much larger for the MUT. Statistically the price change effect $(F(1,8)=5.70, P$ $=0.04)$, genotype effect $(F(1,8)=10.31, P=0.01)$ were significant but the price-genotype interaction effect $(F(1,8)=$ $4.28, P=0.07$ ) not significant. As implied by Fig. (5C), one way ANOVA analysis by genotype showed that decreasing the price of high fat food resulted in a statistically significant increase in the AUC for the MUT $(F(1,5)=10.82, P=0.02)$ but not for the WT $(F(1,3)=0.06, P=0.82)$. Results suggest there is a reduction in glucose tolerance when prices of high fat food are low. However, neither genotype showed an overt glucose intolerance phenotype with low-priced high fat food.

\section{DISCUSSION}

Mice models offer numerous advantages in studying gene and environment interactions and implications, but the environment matters. The goal of this research was to mimic the two most salient features of the human food environment, a closed economy with food choices and costs, and determine their implications for the interaction of genes, behavior, and biology in a mouse model. As in studies using other species $[20,21,23,42]$, this study shows that a choicebased operant chamber closed economy protocol can be applied to mice and mice respond to economic incentives consistent with economic theory. Also, as with operant chamber studies from other investigators, a similar " $N$ " was used, with similar statistical power (e.g. [43, 44]). We furthermore found results in the mouse model very consistent with what has been observed in human populations. Across genotypes, as the price of high fat food decreased relative to low fat food there were increases in high fat food intake, total food intake, body weight, body fat percentage, and area under the glucose tolerance test curve, all statistically significant. As the two foods were isocaloric, the fact that low fat food intake decreased but total intake increased indicates that the degree of substitution is less than one-for-one between the two foods and thus total caloric intake increased leading to an increase in weight, body fat percentage, and area under the curve. Leptin and ghrelin did increase numerically with a decrease in the price of high fat food, but the results were not statistically significant at any reasonable significance levels. One possible reason for the lack of statistically significant results for leptin and ghrelin may have been the relatively short duration of the experimental conditions ( $\sim$ four weeks). As indicated in the introduction, we are not aware of other foraging/cost experiments that have looked at leptin and ghrelin, but the diet-induced obesity literature has documented changes in all three of these phenotypes in ad lib no choice settings [15, 45], again underscoring the need for more research on the 
interaction of economic based choices, genotype responses, and phenotype outcomes.

A.

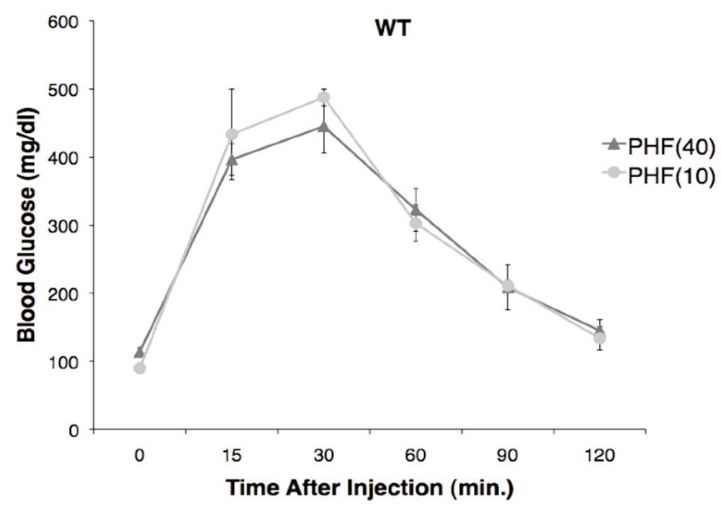

B.

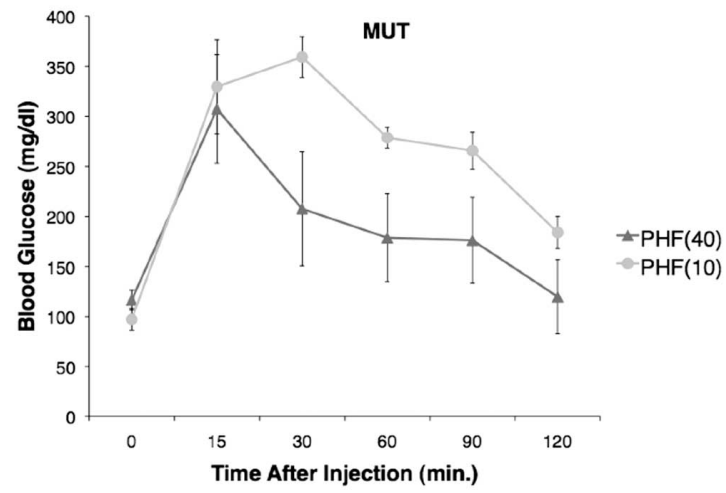

C.

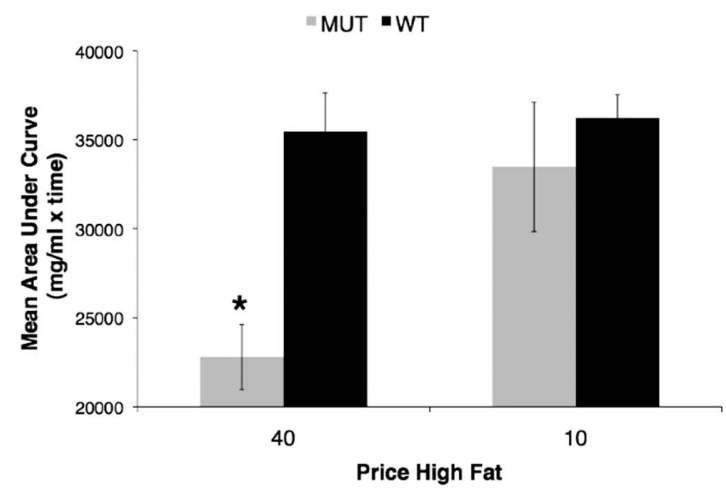

Fig. (5). Glucose tolerance tests versus price change by genotype. Group mean glucose tolerance test curve versus price for WT (A) and MUT (B). "PHF" = Price of High Fat, $(\mathbf{C})$ Group mean \pm SE for changes in area under glucose tolerance test curve versus price change by genotype, ${ }^{*} P<.05$ MUT at $40 v s$ MUT at 10 .

One of the goals was to also consider genotype effects as there is no reason to suspect, a priori, that different genotypes (humans or mice) will respond the same in either the same environment or more importantly across different environments. Within our closed economy environment, we find that generally the MUT and WT mice respond numerically and statistically very similarly in the intake, weight, ghrelin, and leptin dimensions, but differ in the body fat percentage and area under the glucose tolerance test curve. The MUT mice showed a statistically significant higher increase in body fat percentage and higher area under the glucose curve as the price of the high fat food decreased.
Both of these phenotypes are consistent with obesity, and suggest that genetically obese animals may show altered biological responses, to a closed economy environment, with respect to GTT and body fat levels, as compared to WT animals.

The intake and weight outcomes for the MUT and WT in our closed economy environment are in contrast to those obtained by Coyle, Strand, and Good [31] with MUT and WT mice of a similar age and over a similar time frame (520 weeks) but in an ad lib no choice single food environment. Specifically, Coyle, Strand, and Good [31] report a daily mean consumption for WT of $\sim 4.30 \mathrm{~g} /$ day but for MUT $\sim 4.0 \mathrm{~g} /$ day $(P<0.01)$, indicating MUT mice ate less than WT in their ad lib setting. Another study by Wang and colleagues also reports hypophagia in Tub mutant mice [46]. Conversely, in the operant chamber closed economy environment, daily mean total intake for each genotype was about half of the expected ad lib intake, and there were no significant differences between MUT and WT. Specifically, at $20 \mathrm{mg}$ per pellet, our daily mean total consumption over the length of this study was $\sim 2.16 \mathrm{~g}$ /day for MUT and $\sim 1.92 \mathrm{~g} /$ day for WT but these amounts were not statistically different. Some of these discrepancies may be attributable to differences in kcals/gram. Our pellets had $3.77 \mathrm{kcals} /$ gram, whereas the standard chow fed by Coyle, Strand, and Good [31] had $3.02 \mathrm{kcals} / \mathrm{gram}$, but these differences do not contribute to the reversal in relative consumption between genotypes. Thus, in our closed economy environment, hypophagia for the MUT mice disappears.

With respect to weight, Coyle, Strand, and Good [31] found the MUT weighed significantly more compared to the WT over the course of their single food $a d$ lib feeding study. Of note, that study used male mice, which generally weigh more than females. Females, on the other hand, generally have more body fat, and our results in this area (discussed below) do indicate a genotype difference. Overall, the weight response differences between MUT and WT in the ad lib single food setting versus the closed economy choice cost setting underscore the importance of the economic environment and the role choices and costs can play in obesity related phenotypes. Significant weight differences in an ad lib food setting may not imply significant differences in a choice and food costs setting and vice versa.

Alternatively, our finding of a statistically significant difference in body fat percentage between the MUT and WT mice is consistent with the carcass fat content analysis performed by Coyle, Strand, and Good in their ad lib setting [31] and thus the economic environment does not attenuate body composition differences in this analysis.

This research has answered calls for more analysis on the interactions of economics and genetics by incorporating a key feature of economic decision-making: choice and cost. The approach appears promising. Food choice is especially important for biological outcomes, as the outcomes may depend more on the composition of foods consumed rather than the actual intake of a single food. In addition, most choice/substitute research has focused on behavioral issues and effects and not on the biological implications. Moving to studying the biological effects of economic factors is an important research area because many government policies designed to fight obesity are economic policies, such as 
raising prices of certain foods via taxes [47, 48], and these policies not only have direct effects but can also have indirect substitution effects through their influence on the choices of alternative foods. Indeed recent research on human consumption has shown that the decrease in caloric intake and weight due to imposing a tax on sugar sweetened beverages is overestimated when the substitution effects are ignored [49]. The complete efficacy and effectiveness of these policies in improving health cannot be fully appreciated until we understand not only the behavioral but, the biological influences of choice on obesity. In addition, neuroeconomic research that incorporates choice will give us a better understanding of how choices are actually made and the factors that affect choices.

\section{ACKNOWLEDGEMENTS}

This work was supported by a grant from the Fralin Life Science Institute and the Institute for Society, Culture and Environment Obesity Grant Program. The authors would like to thank Ms. Hiayan Zhang, Ms. Emily Hairfield, Ms. Tamima Hossain and the Integrated Life Sciences Building Vivarium Animal Care staff for excellent technical assistance as well as Ms. Ellie Rahochik for editorial assistance and manuscript critique. The authors have no conflict of interest to declare.

\section{CONFLICT OF INTEREST}

The authors confirm that this article content has no conflict of interest.

\section{REFERENCES}

[1] Cordain L, Eaton SB, Sebastian A, et al. Origins and evolution of the Western diet: health implications for the 21 st century. Am J Clin Nutr 2005; 81(2): 341-54.

[2] Drewnowski A. Fat and sugar: an economic analysis. J Nutr 2003;133(3): 838S-40.

[3] Putnam J, Allhouse J, FKantor LS. U.S. per capita food supply trends: more calories, refined carbohydrates and fats. Food Rev 2002; 25: 2-15.

[4] Chou SY, Grossman M, Saffer H. An economic analysis of adult obesity: results from the Behavioral Risk Factor Surveillance System. J Health Econ 2004; 23(3): 565-87.

[5] Drewnowski A, Darmon N. Food choices and diet costs: an economic analysis. J Nutr 2005;135(4): 900-4.

[6] Finkelstein EA, Ruhm CJ, Kosa KM. Economic causes and consequences of obesity. Annu Rev Public Health 2005; 26: 23957.

[7] Hill JO, Sallis JF, Peters JC. Economic analysis of eating and physical activity: a next step for research and policy change. Am J Prev Med 2004; 27(3 Suppl):111-6.

[8] Duffey KJ, Gordon-Larsen P, Shikany JM, Guilkey D, Jacobs DR, Jr., Popkin BM. Food price and diet and health outcomes: 20 years of the CARDIA Study. Arch Intern Med 2010; 170(5): 420-6.

[9] Monsivais P, Drewnowski A. The rising cost of low-energy-density foods. J Am Diet Assoc 2007;107(12): 2071-6.

[10] Powell LM. Fast food costs and adolescent body mass index: evidence from panel data. J Health Econ 2009; 28(5): 963-70.

[11] Vaughan $\mathrm{CH}$, Rowland NE. Meal patterns of lean and leptindeficient obese mice in a simulated foraging environment. Physiol Behav 2003; 79(2):275-9.

[12] Collier G. Operant methodologies for studying feeding and drinking. In: Toates FM, Rowland NE, Eds. Feeding and Drinking. Amsterdam; New York: Elsevier 1987. p. xvii, 570 p.

[13] Hill JO, Lin D, Yakubu F, Peters JC. Development of dietary obesity in rats: influence of amount and composition of dietary fat. Int J Obes Relat Metab Disord 1992; 16(5): 321-33.

[14] Levin BE, Dunn-Meynell AA, Ricci MR, Cummings DE. Abnormalities of leptin and ghrelin regulation in obesity-prone juvenile rats. Am J Physiol Endocrinol Metab 2003; 285(5): E94957.

[15] Lin S, Thomas TC, Storlien LH, Huang XF. Development of high fat diet-induced obesity and leptin resistance in C57Bl/6J mice. Int J Obes Relat Metab Disord 2000; 24(5): 639-46.

[16] Munzberg H, Flier JS, Bjorbaek C. Region-specific leptin resistance within the hypothalamus of diet-induced obese mice. Endocrinology 2004;145(11): 4880-9.

[17] Collier G, Johnson DF. Who is in charge? Animal vs experimenter control. Appetite 1997 ; 29(2):159-80

[18] Timberlake W, Peden BF. On the distinction between open and closed economies. J Exp Anal Behav 1987; 48(1): 35-60.

[19] Vaughan CH, Moore MC, Haskell-Luevano C, Rowland NE. Meal patterns and foraging in melanocortin receptor knockout mice. Physiol Behav 2005; 84(1): 129-33.

[20] Belke TW, Pierce WD, Duncan ID. Reinforcement value and substitutability of sucrose and wheel running: implications for activity anorexia. J Exp Anal Behav 2006; 86(2):131-58.

[21] Kagel JH, Battalio RC, Green L. Economic choice theory: An experimental analysis of animal behavior. New York: Cambridge University Press 1995.

[22] Lea SE, Roper TJ. Demand for food on fixed-ratio schedules as a function of the quality of concurrently available reinforcement. J Exp Anal Behav 1977; 27(2): 371-80.

[23] Green L, Freed DE. The substitutability of reinforcers. J Exp Anal Behav 1993; 60(1): 141-58.

[24] Hursh SR. Economic concepts for the analysis of behavior. J Exp Anal Behav 1980; 34(2): 219-38.

[25] Collier G, Hirsch E, Hamlin PH. The ecological determinants of reinforcement in the rat. Physiol Behav 1972; 9(5): 705-16.

[26] Kaufman LW, Collier G, Hill WL, Collins K. Meal cost and meal patterns in an uncaged domestic cat. Physiol Behav 1980; 25(1): 135-7.

[27] Rowland NE, Vaughan $\mathrm{CH}$, Mathes CM, Mitra A. Feeding behavior, obesity, and neuroeconomics. Physiol Behav 2008; 93(12): 97-109.

[28] Varian H. Intermediate microeconomics: A modern approach. $7^{\text {th }}$ ed. New York: Norton \& Company 2006.

[29] Kleyn PW, Fan W, Kovats SG, et al. Identification and characterization of the mouse obesity gene tubby: a member of a novel gene family. Cell 1996; 85(2): 281-90.

[30] Noben-Trauth K, Naggert JK, North MA, Nishina PM. A candidate gene for the mouse mutation tubby. Nature 1996; 380(6574): 5348.

[31] Coyle CA, Strand SC, Good DJ. Reduced activity without hyperphagia contributes to obesity in Tubby mutant mice. Physiol Behav 2008; 95(1-2): 168-75.

[32] Backberg M, Madjid N, Ogren SO, Meister B. Down-regulated expression of agouti-related protein (AGRP) mRNA in the hypothalamic arcuate nucleus of hyperphagic and obese tub/tub mice. Brain Res Mol Brain Res 2004;125(1-2):129-39.

[33] Guan XM, Yu H, Van der Ploeg LH. Evidence of altered hypothalamic pro-opiomelanocortin/ neuropeptide Y mRNA expression in tubby mice. Brain Res Mol Brain Res 1998; 59(2): 273-9.

[34] Mathis CE, Johnson DF, Collier G. Food and water intake as functions of resource consumption costs in a closed economy. J Exp Anal Behav 1996; 65(3): 527-47.

[35] Maddatu T, Naggert JK. Allele-specific PCR assays for the tub and cpefat mutations. Mamm Genome 1997; 8(11): 857-8.

[36] Reeves PG, Nielsen FH, Fahey GC, Jr. AIN-93 purified diets for laboratory rodents: final report of the American Institute of Nutrition ad hoc writing committee on the reformulation of the AIN-76A rodent diet. J Nutr 1993;123(11): 1939-51.

[37] Wagner AR, Logan FA, Haberlandt K, Price T. Stimulus selection in animal discrimination learning. J Exp Psychol 1968; 76(2): 17180 .

[38] Martin-Garcia E, Burokas A, Kostrzewa E, et al. New operant model of reinstatement of food-seeking behavior in mice. Psychopharmacology (Berl) 2011; 215(1): 49-70.

[39] Golde WT, Gollobin P, Rodriguez LL. A rapid, simple, and humane method for submandibular bleeding of mice using a lancet. Lab Anim (NY) 2005; 34(9): 39-43.

[40] Ziliak ST, McCloskey DN. The cult of statistical significance : how the standard error costs us jobs, justice, and lives. Ann Arbor: University of Michigan Press 2008. 
[41] Lehmann EL. Testing statistical hypotheses. $2^{\text {nd }}$ ed. New York: Springer 1997.

[42] Hursch SR. The economics of daily consumption controlling food and water reinforced responding. J Exp Anal Behav 1978; 29(475491): 475-91.

[43] Atalayer D, Rowland NE. Comparison of voluntary and foraging running wheel activity on food demand in mice. Physiol Behav 2011; 102(1): 22-9.

[44] Atalayer D, Rowland NE. Effects of meal frequency and snacking on food demand in mice. Appetite 2012; 58(1): 117-23.

[45] Dunn GA, Bale TL. Maternal high-fat diet promotes body length increases and insulin insensitivity in second-generation mice. Endocrinology 2009; 150(11): 4999-5009.
[46] Wang Y, Seburn K, Bechtel L, et al. Defective carbohydrate metabolism in mice homozygous for the tubby mutation. Physiol Genomics 2006 ; 27(2): 131-40.

[47] Brownell KD, Frieden TR. Ounces of prevention--the public policy case for taxes on sugared beverages. N Engl J Med 2009; 360(18): $1805-8$.

[48] Kim D, Kawachi I. Food taxation and pricing strategies to "thin out" the obesity epidemic. Am J Prev Med 2006; 30(5): 430-7.

[49] Dharmasena S, Capps O, Jr. Intended and unintended consequences of a proposed national tax on sugar-sweetened beverages to combat the U.S. obesity problem. Health Econ 2012; 21(6): 669-94.

(C) Davis et al.; Licensee Bentham Open.

This is an open access article licensed under the terms of the Creative Commons Attribution Non-Commercial License (http://creativecommons.org/licenses/by$\mathrm{nc} / 3.0 /$ ) which permits unrestricted, non-commercial use, distribution and reproduction in any medium, provided the work is properly cited. 